\title{
TUMOR INFLAMATORIO DE POTT. DESCRIPCIÓN DE UN CASO
}

\section{Pott's Puffy tumor. Case report}

\author{
Carmen SALOM-COVEÑAS; Juan Ramón BENITO-NAVARRO; Ana GUTIÉRREZ-GALLARDO; Eulalia \\ PORRAS-ALONSO \\ Hospital Universitario de Puerto Real. Servicio de Otorrinolaringología. Puerto Real. Cádiz. España. \\ Correspondencia:carmen_salom@hotmail.com
}

Fecha de recepción: 3 de mayo de 2020

Fecha de aceptación: 30 de mayo de 2020

Fecha de publicación: 31 de mayo de 2020

Fecha de publicación del fascículo: 1 de diciembre de 2020

Conflicto de intereses: Los autores declaran no tener conflictos de intereses

Imágenes: Los autores declaran haber obtenido las imágenes con el permiso de los pacientes

Política de derechos y autoarchivo: se permite el autoarchivo de la versión post-print (SHERPA/RoMEO)

Licencia CC BY-NC-ND. Licencia Creative Commons Atribución-NoComercial-SinDerivar 4.0 Internacional

Universidad de Salamanca. Su comercialización está sujeta al permiso del editor

RESUMEN: Introducción y objetivo: El tumor inflamatorio de Pott se describe como una inflamación en la región frontal debido la formación de un absceso subperióstico y osteomielitis del hueso frontal; debido en la mayoría de las ocasiones, a una sinusitis frontal. Es más frecuente observarlo en adolescentes. El objetivo de nuestro estudio es presentar un diagnóstico un tanto olvidado y poco frecuente; así como su descripción como entidad en la discusión de los artículos más relevantes de la literatura. Descripción: Presentamos el caso de un varón de 61 años con cefalea punzante a nivel supraciliar derecha, sin insuficiencia respiratoria nasal y con fibroscopia prácticamente anodina. En la inspección se observa una inflamación, dolorosa a la palpación, del tejido blando con una pequeña fistulización hacia la piel y salida de material purulento. En el TC de senos paranasales se observa una sinusitis crónica frontal derecha. Dicho seno presenta una solución de continuidad en su pared anterior que comunica las partes blandas. Se realiza Draf III del seno frontal derecho guiado con neuronavegador con abordaje combinado externo y vancomicina IV intrahospitalaria. Actualmente el paciente se encuentra asintomático sin clínica infecciosa. Discusión: el tumor inflamatorio de Pott es una complicación rara, pero potencialmente mortal de la sinusitis bacteriana, que consiste en un absceso subperióstico y osteomielitis del hueso frontal. Se diagnostica con tomografía computarizada con contraste o resonancia magnética y se trata con antibióticos de amplio espectro, así como intervención 


\section{TUMOR INFLAMATORIO DE POTT. DESCRIPCIÓN DE UN CASO \\ SALOM-COVEÑAS C; BENITO-NAVARRO J R; GUTIÉRREZ-GALLARDO A; PORRAS-ALONSO E}

quirúrgica de forma precoz. Es necesario conocer la fisiopatología y manejo del cuadro; evitando así las posibles complicaciones intracraneales. Conclusiones: el diagnóstico precoz de esta entidad y el tratamiento antibiótico y endoscópico son esenciales para evitar el riesgo de progresión hacia complicaciones neurológicas graves subsidiarias de tratamientos quirúrgicos más agresivos.

PALABRAS CLAVE: tumor inflamatorio de Pott; osteomielitis del hueso frontal.

SUMMARY: Introduction and objective: Pott's puffy tumor is described as inflammation in the frontal region due to the formation of a subperiotic abscess and osteomyelitis of the frontal bone, due in most cases, to frontal sinusitis. It is common to see in adolescents. The goal of our study is to present a forgotten and uncommon diagnosis, as well as its description as an entity in the discussion of the most relevant articles of literature. Description: A 61-year-old male that had puncture headache at the right supraciliary level, without nasal respiratory failure and with anodyne fibroscopy. In the inspection there is an painful inflammation of the soft tissue with a small fistulization to the skin with purulent material.Frontal chronic sinusitis is observed in the CT. A continuity solution on its anterior wall that communicates the soft parts. Draf III of the right frontal sinus guided with neuronavigator, external combined approach and intrahospital vancomycin IV were used as treatment. Currently the patient is asymptomatic without infectious clinic. Discussion: Pott's puffy tumor is a rare but potentially deadly complication of bacterial sinusitis that consists of subperiosteal abscess and osteomyelitis of the frontal bone. It is best diagnosed with computerized tomography with intravenous contrast or magnetic resonance imaging and treated with early broad-spectrum antibiotics and surgical intervention. It is necessary to know its pathophysiology and management, avoiding intracranial complications. Conclusions: early diagnosis of this entity, antibiotic and endoscopic treatment are essential to avoid the risk of progression towards serious neurological complications subsidiary to more aggressive surgical treatments.

KEYWORDS: Pott's Puffy Tumor; osteomyelitis of the frontal bone.

\section{INTRODUCCIÓN}

El tumor inflamatorio de Pott es una complicación infrecuente de la sinusitis frontal caracterizado por tumefacción y edema en la frente por un absceso subperióstico secundario a la osteomielitis del hueso frontal [1]. Fue descrito por primera vez en el siglo XVIII por Percivall Pott. Pott describió inicialmente este tumor como una complicación de un trauma local en 1768 y luego como una complicación de la sinusitis frontal en 1775 . El diagnóstico y el tratamiento tardío de esta enfermedad pueden ser responsables de complicaciones intracraneales [2].

A continuación, describiremos un caso clínico del tumor inflamatorio de Pott.

\section{DESCRIPCIÓN}

Varón de 61 años que acude a consulta por cefalea punzante a nivel supraciliar derecha de un mes de evolución. Ausencia de mucosidad y de insuficiencia respiratoria nasal. En la nasofibrolaringoscopia no se aprecia poliposis nasosinusal, pero sí una inflamación de la mucosa a nivel de meato medio en dirección al receso del seno frontal. Durante la inspección se observa una inflamación dolorosa a la palpación del tejido blando de unos $3 \mathrm{~cm}$ con una pequeña fistulización hacia la piel y salida de material purulento (Figuras 1 y 2). Niega antecedente de traumatismo frontal.

En el TC de senos paranasales se observa ocupación completa del seno frontal derecho con aumento de la densidad ósea indicando cronicidad 


\section{TUMOR INFLAMATORIO DE POTT. DESCRIPCIÓN DE UN CASO \\ SALOM-COVEÑAS C; BENITO-NAVARRO J R; GUTIÉRREZ-GALLARDO A; PORRAS-ALONSO E}

del proceso (sinusopatía crónica) que condiciona un adelgazamiento y abombamiento inferior del techo de la órbita (Figura 3). Dicho seno presenta una solución de continuidad en su pared anterior, que comunica las partes blandas anteriores al hueso frontal (que se encuentran engrosadas) al seno (Figura 4). Tratamiento: Draf II A del seno frontal derecho guiado con neuronavegador con abordaje combinado externo supraciliar (drenaje de la colección y exéresis del hueso osteomielítico

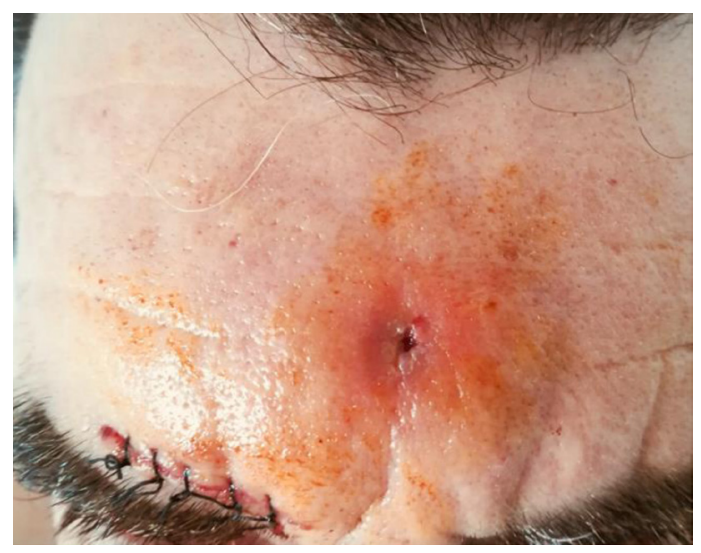

Figura 1. Orificio de fistulización a piel con tumefacción. Sutura de abordaje externo.

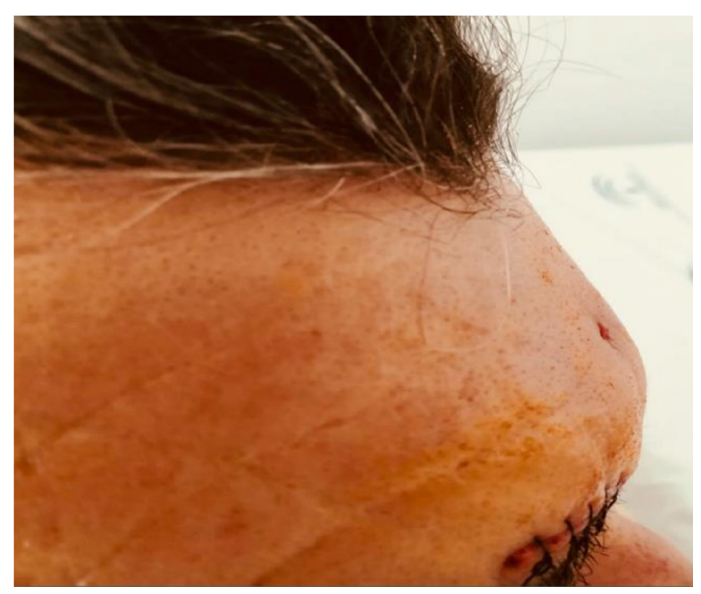

Figura 2. Orificio de fistulización a piel con tumefacción. Sutura de abordaje externo. del seno frontal) (Figuras 1 y 2) y vancomicina IV intrahospitalaria durante 7 días. Al mes de la intervención continuaban las molestias frontales la persistencia de salida de material purulento a nivel de la fístula cutánea, así como el velamiento del seno frontal en la nueva prueba de imagen; con lo que se reinterviene; en esta ocasión con un abordaje endoscópico más agresivo, Draf III (Figura 5); utilizando nuevamente el neuronavegador. Tras esta intervención el paciente se encuentra actualmente asintomático y ha desaparecido la clínica infecciosa.

\section{DISCUSIÓN}

Percival Pottdescribió por primera vez el tumor de Pott como una tumoración circunscrita del cuero cabelludo y una separación del pericráneo del cráneo en virtud de dicho tumor. Se trata de una osteomielitis frontal con absceso subperióstico del hueso frontal [1,2].

Esta patología puede suceder en cualquier rango etario; sin embargo, en los estudios revisados parece haber una incidencia mayor en la adolescencia $[3,4]$; siendo más frecuente en varones, sin saber el porqué de esta predominancia en el género [1,3,5]; encontrándose una ratio de 3.5:1 respecto a la mujer en la revisión de Tatsumi et al [6].

La causa más frecuente es la sinusopatía frontal de larga data, aislada o en el contexto de una pansinusitis $[5,6,7]$. Clarós et al describe en su artículo el tumor de Pott con antecedente de trauma frontal previo [3]; que es la segunda causa en frecuencia. Se han descrito otras menos frecuentes como las picaduras de insectos, tumores malignos, la acupuntura [1]; y recientemente algún caso aislado al consumo intranasal de cocaína [8].

El conocimiento de la anatomía y la embriología del seno frontal es fundamental para entender la patogénesis del tumor inflamatorio de Pott. Los senos frontales alcanzan su máximo desarrollo a los 13 años; $y$ es el momento en el que la vascularización de las venas diploicas (responsables del drenaje del seno frontal y que comunican con el 


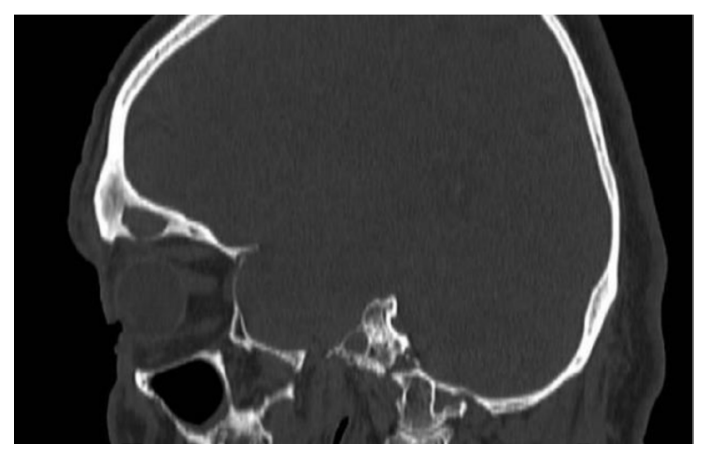

Figura 3. TC de senos paranasales, corte sagital.

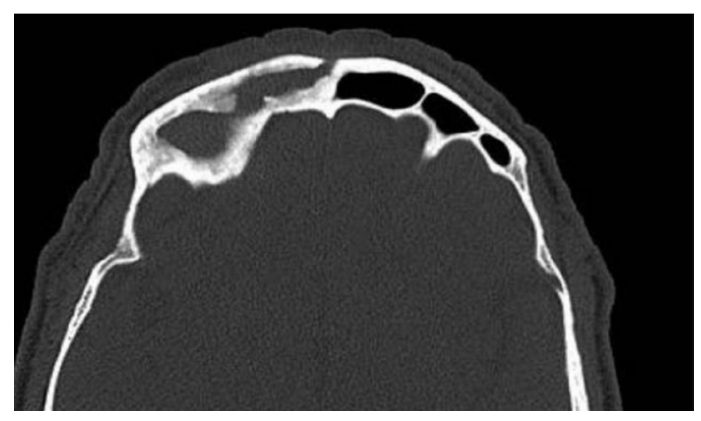

Figura 4. TC de senos paranasales corte axial.

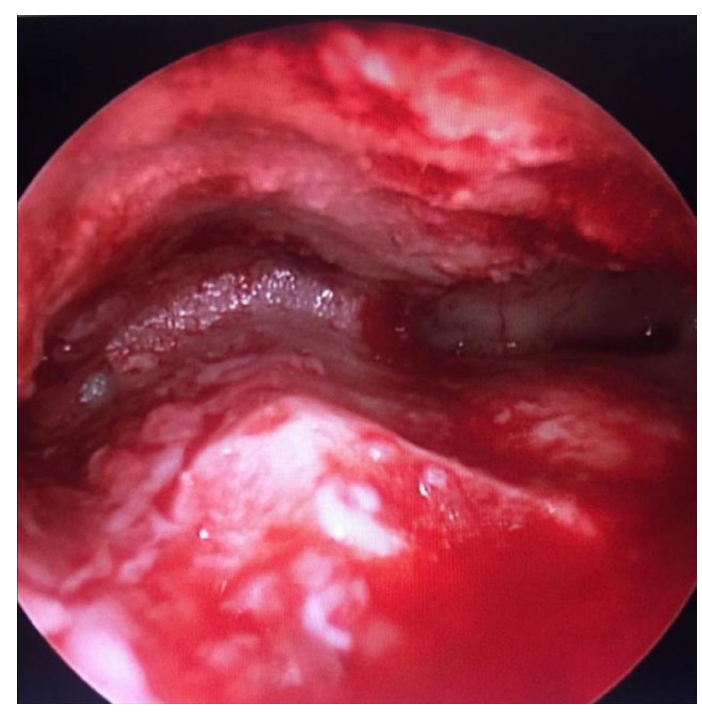

Figura 5. Imagen endoscópica tras la cirugía Draft III. seno venoso dural) alcanzan su pico; esto explicará las complicaciones intracraneales sin la extensión directa del hueso en los adolescentes [8,9]. Por lo tanto, la infección puede diseminarse, directamente por la erosión de la pared posterior del seno frontal o bien a través de émbolos sépticos a por las venas diploicas hacia la duramadre [7]. Los gérmenes más frecuentemente implicados son el Staphylococcus aureus, Staphylococcusepidermidis y las bacterias anaerobias (estas últimas se ven en mayor frecuencia asociadas a las complicaciones intracraneales) [3,7]. En nuestro paciente se consiguió aislar una muestra con flora mixta de Staphylococcus aureus y Bacteroides.

Los síntomas pueden variar desde cefaleas, tumefacción periorbitaria, tumoración a nivel de la frente, fístula cuánea, fiebre y rinorrea purulenta. La clínica que sugiere participación intracraneal incluye fiebre, convulsiones, cefalea, letargo, vómitos y déficits neurológicos focales [1,9].

La identificación de esta patología y el manejo inmediato son esenciales para evitar complicaciones intracraneales. El diagnóstico del tumor Pott se basa en hallazgos clínicos y radiológicos. El TC craneal es la prueba de imagen de elección; que, además de identificar las complicaciones intracraneales y extracraneales asociadas con la sinusitis frontal $[7,10]$; pueden observase otra serie de factores que propician a un receso del frontal estrecho o hasta su completa obstrucción; como pueden ser: bulla etmoidal muy neumatizada, cornete medio excesivamente neumatizado y celda de ager nasi de gran tamaño [11]. La RNM, ayuda a esclarecer aún más la extensión de la enfermedad intracraneal $[7,10]$.

En el caso de que se den complicaciones intracraneales Dusu et al recomienda la realización de TC postquirúrgicos seriados al séptimo, duodécimo y vigésimo día para comprobar la completa resolución del cuadro [5].

El diagnóstico diferencial para cualquier tumefacción frontal, como ocurre con nuestro paciente, incluye: el quiste sebáceo infectado, 


\section{TUMOR INFLAMATORIO DE POTT. DESCRIPCIÓN DE UN CASO \\ SALOM-COVEÑAS C; BENITO-NAVARRO J R; GUTIÉRREZ-GALLARDO A; PORRAS-ALONSO E}

quistes dermoides, lipomas, lipomas intraóseos, lipoblastomas, mucoceles de seno frontal, pseudoaneurismas de la arteria temporal superficial y tumores malignos; como metástasis o meningiomas frontales agresivos [12].

Entre las complicaciones intracraneales se encuentran el empiema subdural, absceso cerebral, celulitis orbitaria, absceso intraotbitario, trombosis venosa y absceso epidural [9]. Kenteki et al en su revisión expone que estas complicaciones ocurren entre un $60-80 \%$ de los pacientes con tumor de Pott [13]. Tsai et al en su serie de 10 casos pediátricos observó que el 100\% presentaban complicaciones intracraneales [14]; sin embargo, Akillama et al en su revisión sistemática, la incidencia fue de un $29 \%$, quizás porque no se incluyeron series de pacientes pediátricos [15].

El drenaje quirúrgico externo era el método histórico de manejo del tumor de Pott [15].

El drenaje quirúrgico endoscópico temprano, así como el tratamiento antibiótico asociado de forma prolongada es actualmente el pilar de la terapia, siendo suficientes para la resolución completa del cuadro; como se describe en algunas series $[15,16]$.

La presencia de infección sinusal residual, que fue lo que ocurrió en nuestro caso; después del drenaje inicial o la respuesta inadecuada a los antibióticos pueden necesitar una cirugía de seno frontal más extensa; como el Draf III y siempre que se pueda, guiado con neuronavegador. En el caso de que presenten osteomielitis más avanzada donde se ha desarrollado el secuestro óseo, también pueden beneficiarse de un procedimiento Draf III, donde el seno puede irrigarse mejor $[15,16]$.

Los pacientes con tumor de Pott que presentan complicaciones intracraneales tienden a requerir drenaje quirúrgico en forma de craneotomía $[16,17]$.

En lo que respecta tratamiento antimicrobiano debe adaptarse a los resultados del análisis del cultivo bacteriológico obtenido. Es necesario que los antibióticos seleccionados crucen la barrera hematoencefálica y cubran tanto la flora aeróbica como la anaeróbica. La combinación ideal sería penicilina o vancomicina, cefalosporina de tercera generación y metronidazol. El uso de antibióticos debe extenderse al menos durante 4 a 8 semanas después de la cirugía [18].

El pronóstico, en general, es favorable, incluso si los síntomas neurológicos están presentes al ingreso; obviamente, el reconocimiento del cuadro y el tratamiento precoz oportunos son necesarios para obtener resultados exitosos [17].

\section{CONCLUSIONES}

El tumor inflamatorio de Pott es una entidad muy rara que debe sospecharse como una complicación grave de la sinusitis frontal en pacientes pediátricos y adultos.

La sospecha clínica, el diagnóstico y tratamiento precoz de esta patología son esenciales para evitar las complicaciones intracraneales. Cada vez hay más estudios que demuestran que el tumor de Pott se puede manejar con éxito mediante un enfoque endoscópico combinado con terapia prolongada de antibióticos. La disponibilidad de instrumentos en ángulo motorizados y sistemas de guía de imágenes ha proporcionado a los otorrinolaringólogos una alternativa a las técnicas abiertas tradicionales.

\section{BIBLIOGRAFÍA}

1. Ainsa D, Pons S, Muñoz A, Vega M, Otero M. Tumor inflamatorio de Pott: una complicación infrecuente de la sinusitis frontal. An Pediatr.2014;80(5):317-20.

2. Pott P. Observations on the nature and consequences of wounds and contusions of the head, fractures of the skull, contusions of the brain. Hitch and Haws.1760;22:56-8.

3. Clarós P, Ahmed H, Clarós A. Posttraumatic Pott's puffy tumour: A case report. Eur Ann Otorhinolaryngol.2016; 133: 118-21. 


\section{TUMOR INFLAMATORIO DE POTT. DESCRIPCIÓN DE UN CASO \\ SALOM-COVEÑAS C; BENITO-NAVARRO J R; GUTIÉRREZ-GALLARDO A; PORRAS-ALONSO E}

4. Swan P, Mogal S, Chaudary S. Pott's puffy tumor: an uncommon clinical entity. Case Rep Pediatr.2012;1012:1-4.

5. Dusu K, Chandrasekharan D, Yaghchi C, Quiney R. A huge Pott's puffy tumour swcondary to pansinusitis.BMJ.2019;12: e229755.

6. Tatsumi S, Ri M, Higashi N, Wakayama N, Matsune S, Tosa M. Pott's puffy Tumor in an adult: A case report and Review of literatura. J Nippon Med.2016; 83(5): 2114.

7. Koltsidopoulos P, Papageorgiou E, Skoulakis C. Acute sinusitis complicated with Pott puffy tomour. CMAJ.2019;191(6): E165.

8. Noskin GA; Kalish Sb. Pott's puffy tumor: a complication of intranasal cocaine abuse. Rev Infect Dis.1991;13: 606-8.

9. Shrarma P, Sharma S, Gupta N, Kochar P, Kumar Y. Pott puffy tumor. Proc (Bayl Univ Med Cent).2017;30(2):179-81.

10. Apostolakos D, Tang I. Image Diagnosis: Pott Puffy tumor. Perm J.2016; 20(3):153157.

11. Collet S, Grulois V, Eloy P, Rombaux P, Bertrand B.A Pott's puffy tumour as a late complication of a frontal sinus reconstruction: case report and literatura review. Rhinology.2009; 47:470-5.
12. Shemesh AJ, Panebianco NL, Chen AE: An uncommon complication of sinusitis in a young adolescent. Pediatr Emerg Care.2015; 31:531-2.

13. Ketenci I, Unlu Y, Tucer B. The Pott's puffy tumor: a dangerous sign for intracranial complications. Eur Arch Otorhinolaryngol.2011;268:1755-63.

14. Tsai BY, Lin KL, Lin TY, et al. Pott's puffy tumor in children. Childs Nerv Syst. 2010; 26:53-60.

15. Akkiyama K, Karaki M, Mori N. Evaluation of adult Pott's puffy tumor: our five cases and 27 literature Cases. Laryngoscope.2012; 122: 2382-8.

16. Leong S, Phil M. Minimally invasive surgery for Pott's Puffy tumor: is it time for a paradigm shift in managing a 250year-old problem? Ann Otol Rhinol Laryngol.2017;126(6):433-7.

17. Pololsky G, Santos M, Carneiro V, Pires L, Pacheco R, Santos R. Neurosurgical Management of Pott's puffy tumor in ano bese adolescent with asthma: case report with a brief review of the literatura. Cureus. 2018;10(6):2836.

18. Peric A, Milojevic M, Ivetic C. A Pott's Puffy Tumor Associated with Epidural-Cutaneous Fistula and Epidural Abscess: Case Report. Balkam Med J.2017; 34:284-7. 